\title{
Situación actual de las titulaciones académicas en Europa sobre restauración del patrimonio histórico
}

\author{
Raniero Baglioni \\ Asesor técnico en Conservación Preventiva del IAPH \\ $M^{2}$ José González López. Profesora \\ Titular en la Facultad de Bellas Artes de Sevilla
}

\section{Introducción: breve evolución de la profesión}

Hoy día la profesión de restaurador de bienes culturales está en curso de transformación. Las desigualdades existentes entre los niveles formativos, el reconocimiento y las competencias de estos profesionales en nuestro país y en los respectivos países de la Comunidad Europea, están ocasionando una toma de conciencia del problema existente por parte de la Administraciones dedicadas al Patrimonio Cultural y también por parte de los Ministerios de Educación respectivos. De igual forma existe una concienciación pública y social de la importancia que para la salvaguarda del patrimonio cultural, adquiere la figura profesional del conservador-restaurador de bienes culturales del patrimonio mueble, tanto por parte de este colectivo, como por el de otras disciplinas implicadas, y también, por parte del mundo de la administración y político.

Hoy día es impensable la concepción tradicional del restaurador que ejecuta su trabajo de forma aislada e intuitiva y con respuestas a todas las demandas que plantea el proceso de conocimiento del bien y su posterior tratamiento.

Esta concepción tradicional comienza a modificarse en la década de los ochenta con el documento presentado por el Grupo de trabajo para la formación en conservación y restauración del ICOM titulado: El Conservador-Restaurador una definición de la profesión publicado en el Congreso Trienal del ICOM celebrado en Copenhagen en 1984. Para posteriormente consolidarse con la Guía Profesional que elabora la Confederación Europea de Organizaciones de Conservadores-Restauradores (ECCO) en 1993/94.

Ambos documentos han sido considerados como textos básicos y punto de partida, conjuntamente con la Carta de Venecia de 1964, en las Jornadas Preservación del Patrimonio Cultural: hacía un perfil europeo del Conservador-Restaurador, celebradas en Pavia del 28 al 22 de octubre del año 1999, siendo por ello objeto de comentario y de síntesis ya que su contenido, facilitó la comprensión de las conclusiones alcanzadas por parte de los expertos en las Jornadas de Pavia.
A su vez las conclusiones de Pavia han abierto nuevas líneas de trabajo en la Unión Europea que se manifiesta a través del Proyecto FULCO, de la asociación ENCORE cuyas línea principales se sintetizan en el Documento de Viena.

\section{Evolución de la profesión a nivel europeo}

Se analizan los principales documentos que desde la década de los 80 hasta la actualidad han marcado la evolución de la profesión del conservador-restaurador a nivel europeo.

a. Del restaurador de Bienes Culturales al Conservador -Restaurador de Bienes Culturales

Este paso se produce conceptualmente con la publicación del documento El Conservador-Restaurador una definición de la profesión. Esta distinción es claramente significativa y está estrechamente vinculada con las competencias y actividades que con mayor medida desempeñan y le son demandadas. Su campo de acción se ve ampliado desde el meramente cognoscitivo (examen/diagnosis) y operativo (aplicación de los tratamientos necesarios, conservación, restauración) a las derivadas de su preservación y salvaguarda (entorno, manipulación, mantenimiento), - conservación preventiva

Desde el momento en que se toma conciencia por parte de la sociedad y también por parte de este colectivo, de la importancia que ejerce el restaurador en el Patrimonio Cultural de un país o región, desde el punto de vista que "opera" directamente sobre originales con un importante valor cultural, social, histórico, religioso y científico, y de consecuencia sobre el patrimonio a transmitir a generaciones venideras, se analiza el impacto que puede derivarse del desarrollo de su actividad.

\section{b. La confeceración europea de organizaciones de Conservadores Restauradores (ECCO)}

En 1993/94 la Confederación Europea de Organizaciones de conservadores-restauradores (ECCO) redacta un documento denominado Guía Profesional, que constituye hoy día un documento base y actualizado que define con rigor la ética y el perfil de competencias y formativo de esta figura profesional al que se acoge todo profesional asociado a esta Confederación. Este documento se estructura en tres grandes apartados: 
I. La Profesión (definición de las competencias: examen-diagnóstico, conservación preventiva, intervención de conservación y restauración, programas de inspección, asistencia técnica, dirección de proyectos, emisión de informes sin juicio sobre el valor comercial del bien, desarrollar programas educacionales en esta disciplina, difundir la información generada con su investigación o trabajo y por último, fomentar la comprensión de esta disciplina).

II. Código deontológico establece 25 artículos estructurados en cuatro apartados: I. Principios generales para la aplicación del Código, II. Obligaciones hacia el bien cultural, III. Obligaciones de los propietarios y de los custodios legales y IV. Obligaciones hacia los Colegas y hacia la Profesión

III. Requisitos básicos para la educación en Conservación-Restauración plantea la necesidad de definir un programa formativo unánime en cuanto a filosofía, y contenido que abarque las distintas especialidades de esta disciplina y que incluya formación teórica y practicas aplicadas a casuísticas concretas, con objeto de que los profesionales estén suficientemente preparados y capacitados para desempeñar responsablemente el ejercicio de esta profesión de forma interdisciplinar con las profesiones afines y de desarrollar investigaciones aplicadas a la conservación-restauración y a las técnicas históricas.

Es de interés destacar como este documento resalta la necesidad de elevar el nivel formativo de esta profesión, a un grado universitario o equivalente, para mantener su estatus profesional. Para ello plantea una formación a nivel universitario o equivalente a la que se acceda mediante un examen de admisión que valore la aptitud del candidato.

\section{c. Jornadas: Preservación del Patrimonio Cultural: Hacia un Perfil Europeo de Conservador-Restaurador. 18 al 22 de octubre. Universidad de Pavía, Pavía, Italia}

Durante el desarrollo de estas jornadas se pretendió alcanzar los siguientes objetivos:

- Reconocimiento de la Conservación-Restauración como sector autónomo.

- Incremento cualitativo del nivel de formación, en interés de la Conservación y Restauración del Patrimonio Cultural.

- Incorporación de la formación de Restauradores de Sienes Culturales en los programas de la U.E.

- Mejora del rol del Restaurador de Bienes Culturales en relación con otras profesiones ligadas a la tutela del Patrimonio Cultural, y definición en Europa del rol profesional del Restaurador de Bienes Culturales.

- Reconocimiento de la profesión de Restaurador de Bienes Culturales a nivel europeo. Las conclu- siones alcanzadas por los expertos se exponen literalmente:

CONSIDERANDO que el patrimonio cultural, mueble e inmueble, es un componente fundamental de la identidad europea, en el respeto de las diversidades nacionales y regionales;

CONSIDERANDO la naturaleza particular de tal patrimonio, su carácter irrepetible, la obligación moral de transmitirlo a las generaciones presentes y futuras y la necesidad de sensibilizar a los profesionales del sector, ciudadanos y representantes públicos de su génesis, de su historia, de su vulnerabilidad y de su tutela;

CONSIDERANDO la necesidad de garantizar la conservación y la restauración al mayor nivel, es decir, capaz de garantizar la autenticidad y de prolongar su existencia;

CONSIDERANDO que la conservación-restauración de alto nivel debe sustentarse en el reconocimiento urgente del estatus profesional del conservador-restaurador a nivel europeo;

CONSIDERANDO; que el consevador-restaurador debe participar en el proceso de decisión desde la fase de concepción del proyecto de conservaciónrestauración y que debe asumir, en colaboración con las otras profesiones implicadas, las responsabilidades derivadas de su competencia tales como la diagnosis, la definición, la realización y la documentación de los tratamientos.

LOS EXPERTOS de las profesiones implicadas en el sector de la conservación y de la restauración del patrimonio cultural, reunidos en Pavia del 18 al 22 de octubre de 1997, recomiendan que, sobre la base del documento 'E.C.C.O. Professional Guidelines" (anexo I) y en colaboración con todos los especialistas del sector, la Unión Europea sostenga las siguientes acciones:

I. El reconocimiento y la promoción de la conservación y de la restauración como una disciplina, cuya enseñanza se desarrolle, para todas las categorías de los bienes culturales, a nivel universitario o reconocido como equivalente, con acceso al doctorado.

2. La potenciación de la interdisciplinariedad entre los conservadores-restauradores y los representantes de las disciplinas científicas y humanísticas, tanto en la enseñanza como en la investigación.

3. El desarrollo del perfil profesional del conservador-restaurador en base a las normas definidas por E.C.C.O. (93/94), de su participación en el proceso de decisión desde la concepción del proyecto y de su responsabilidad en la comunicación con los profesionales del sector, ciudadanos y representantes públicos.

4. La definición a nivel europeo de la competencia profesional específica del conservador-restaurador.

5. Una particular atención a fin de evitar la proliferación de programas formativos sin la adecuada cualificación.

6. Un justo equilibrio en la formación del conservador-restaurador entre las enseñanzas teóricas y prácticas integradas, así corno la inserción de 
estrategias de comunicación entre las materias de estudio.

7. El establecimiento urgente de un programa de cooperación y de intercambio mediante una red europea de Institutos e Instituciones de formación y de investigación en materia de conservación y de restauración.

8. La realización, por parte de la profesión, de un estudio comparativo de los diversos sistemas formativos (objetivos, contenidos y niveles).

9. Una mejor difusión de la información mediante la publicación de los trabajos relativos a la actividad de conservación-restauración.

10. El desarrollo de la investigación en el sector de la conservación-restauración.

II. La creación de un marco normativo que garantice la calidad de las intervenciones sobre los bienes culturales y su entorno, para evitar los efectos negativos de las presiones del mercado; este marco normativo debe incluir en particular disposiciones relativas a:

- la cualificación de las empresas, o de los grupos de profesionales responsables.

- las especificaciones técnicas de los diversos capítulos para cualquier proyecto de conservación y de restauración.

12. La publicación de un glosario multilingüe basado en la definición conceptual contenida en la bibliografía especializada de la profesión.

13. La disponibilidad de los medios necesarios para asegurar una mejor comunicación entre los profesionales del sector, ciudadanos y representantes públicos.

Los expertos desean que las instituciones comunitarias consideren prioritaria la traducción en acciones concretas y coordinadas de estas recomendaciones. Adoptado por unanimidad en Pavia el 21 de octubre de 1997.

d. Proyecto Fulco y Documento de la Asociación de la Asociaciónencore: debate en el encuentro de Viena 30II al I-12 de 1998

\section{Proyecto FULCO}

El proyecto FULCO pretende ofrecer un borrador de las competencias profesionales requeridas por conservadores/ restauradores, así como facilitar la discusión de la extensión de los métodos para probar esas competencias y buscar el consenso para el uso de los estándars de competencia dentro de la comunidad europea de los profesionales de la conservación-restauración.

Los organizadores holandeses del Proyecto FULCO, conscientes de la necesidad de una amplia consulta mas allá del grupo de asociados que lo redactaron, organizaron un encuentro en Viena con lo representantes de todos los países de la Unión Europea, incluyendo las asociaciones E.C.C.O, ENCORE y la Funda- ción GIOVANNI SECO SUARDO, para presentar el borrador del proyecto y discutir los contenidos.

El debate que ha tenido lugar en Viena ha tratado sobre las deficiencias detectadas en el proyecto FULCO, utilizando a tal fin el documento que la asociación ENCORE presentó en Viena para informar los delegados presentes a la reunión y ser fuente de reflexión, y que a nuestro parecer, refleja ampliamente las dudas y las diferentes opiniones que fueron temas de discusión.

\section{Documento ENCORE}

Centra su contenido en las carencias detectadas en el proyecto FULCO tales como:

- La idoneidad del tema de los estándars para la profesión.

- No hay todavía una definición legal de la profesión o de los profesionales de la conservación-restauración.

- Es también escasa la delimitación con otras profesiones o profesionales que tratan objetos del Patrimonio Cultural.

- La necesidad de un adecuado análisis de la situación actual de la disciplina y de la profesión de la conservación-restauración en Europa.

Documento de Viena - I de diciembre de 1998.

Conclusiones:

I. El reconocimiento legal de la profesión del conservador-restaurador a nivel Europeo ( Pavia $4^{\text {a }}$ Consideración).

2. La armonización de la educación de la conservación-restauración a nivel universitario a equivalente reconocido. (Pavia, Recomendaciones 1,3,6 ). Además los sucesivos pasos deben incluir la publicación de un glosario común para ayudar como refuerzo en la comunicación. (Pavia Recomendación 12)

Además los participantes del encuentro de Viena han identificado los siguientes nuevos objetivos:

3. La necesidad de aclarar un 'nivel universitario o reconocido equivalente';

4. La necesidad de analizar los diferentes marcos legales para regular la salvaguarda del Patrimonio Cultural en los países europeos;

5. La necesidad de analizar el proceso de la conservación-restauración en su contexto, lo que significa identificar la metodología de cada paso y de las áreas implicadas en cada uno de ellos; 
6. La necesidad de progresar a partir de pautas y recomendaciones efectivas hacia criterios comunes de evaluación de actividades, cuyo fin sea la salvaguarda del Patrimonio Cultural, en base a documentos consensuados.

7. La necesidad de identificar las diferentes partes involucradas en la Conservación-Restauración y sus distintivos roles.

8. La necesidad de fomentar el dialogo entre los cuerpos profesionales y organizaciones e instituciones, entes (públicos o privados), administración, y todos aquellos que poseen o son responsable del Patrimonio Cultural, en interés de la salvaguarda de nuestro Patrimonio Cultural.

De igual modo se ha establecido una Agenda para el futuro:

Los participantes en el encuentro de Viena recomiendan encarecidamente a la Comisión Europea y a otras autoridades competentes, que deberían sostener cualquier iniciativa dirigidas a cumplir las anteriores conclusiones, que se llevarán a cabo en asociación con E.C.C.O. y con otros grupos profesionales implicados.

Además, cualquier desarrollo a nivel Europeo de la definición de las competencias del conservador-restaurador deberán ser dirigidas por los mismos profesionales.

Conclusión I será coordinada por E.C.C.O.

Conclusiones 2 y 3 serán coordinadas por ENCO$\mathrm{RE}$, en asociación con el proyecto CONBEFOR.
El desarrollo del glosario será iniciado por la Institución Tecnológica de Educación de Atenas, Departamento de Conservación.

\section{Conclusiones}

Todos estos encuentros y documentos que se están produciendo a nivel internacional nos invitan a todos los profesionales que actuamos directa e indirectamente sobre el Patrimonio Cultural a reflexionar sobre el tema.

Para desarrollar, los objetivos anteriormente descritos, el conservador-restaurador debe poseer determinadas capacidades que son requisitos fundamentales de su profesión. Es obvio que tales capacidades profesionales no pueden ser improvisadas sino el fruto de una formación altamente cualificada sin distinción de niveles o "estándars", que debe estar concebida específicamente para esta figura profesional y articulada mediante un programa de elevado nivel cualitativo, técnico y científico, de duración suficiente, de tal forma que permita dotar de un adecuado nivel a quien accede a esta profesión. Las nuevas corrientes defienden una formación específica, preferiblemente de nivel universitario y con acceso al tercer ciclo.

Es competencia de la Administración Publica y Educativa de nuestro país y de los respectivos países de la Unión Europea dar una solución válida a este gran problema sin que se vean perjudicados los profesionales actualmente en activo, con independencia de la titulación que legalmente han obtenido y que les capacita para el desarrollo de su actividad profesional.

\section{Bibliografía}

Informe sobre el encuentro Europeo "Centres of ecxellence", I5 16 Mayo 1997, Amsterdam, p.46, 2c.

Documento de Pavia, 21 de Octubre de 1997

FULCO, un sistema sobre las competencia de los conservadores-restauradores en Europa. Un tema de discusión para el encuentro de Viena por Kate Foley y Steph Scholten, 16 de Octubre 1998.

Boletín n4. 1987 ICOM. Grupo de Trabajo para la formación en Conservación y Restauración. Versión española "El conservador-restaurador. Una definición de la profesión".
ROMÁN FDEZ-BACA CASARES. Summit Europeo. Tutela del Patrimonio Cultural: Hacía un perfil europeo del restaurador de bienes culturales. Pavia 18-22 de octubre de 1997. Boletín P.H.N'21. 1997, p 8-9.

Ma. JOSÉ GONZÁLEZ LÓPEZ. El conservador-restaurador de bienes culturales: una profesión a debate. Boletín P.H. № 21. 1997, p: II-I4.

RANIERO BAGLIONI, ANA MONTESA KAIJSER. El proyecto "FULCO" un marco de competencia para conservadores-restauradores en Europa. VIENA 1998. Boletín P.H. No 26. 1999, p: 8-14. 